\title{
Field study of anthropomorphic and muscle performance changes among elite skippers following a transoceanic race
}

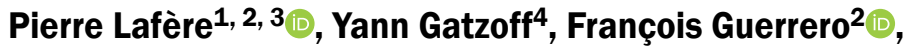 \\ Steven Provyn ${ }^{3,5,6}$, Costantino Balestra ${ }^{3,5,6,7}$ \\ ${ }^{1}$ Department of Anaesthesiology, Erasme University Hospital, Université Libre de Bruxelles, Brussels, Belgium \\ ${ }^{2}$ ORPHY Laboratory EA4324, Université de Bretagne Occidentale, Brest, France \\ ${ }^{3}$ Environmental, Occupational, Ageing (Integrative) Physiology Laboratory, Haute Ecole Bruxelles-Brabant (HE2B), Brussels, Belgium \\ ${ }^{4}$ Geneva University Hospitals, Geneva, Switzerland \\ ${ }^{5}$ Anatomical Research Training and Education (ARTE), Vrije Universiteit Brussel (V.U.B.), Brussels, Belgium \\ ${ }^{6}$ Anatomical Research and Clinical Studies (ARCS), Vrije Universiteit Brussel (V.U.B.), Brussels, Belgium \\ ${ }^{7}$ Motor Sciences, Université Libre de Bruxelles (U.L.B.), Brussels, Belgium
}

\begin{abstract}
Background: Ocean racing has become increasingly demanding, both physically and psychologically. The aim of the study was to assess global changes after a transoceanic race.

Materials and methods: Eight male sailors were evaluated pre- and post-race through anthropometric measurements (weight, skinfold, girth at different level and estimated body fat percentage), multifrequency tetrapolar bioelectrical impedance, muscular performance, visual analogic scale for perceived fatigue and Critical Flicker Fusion Frequencies for cerebral arousal.

Results: Compared to pre-race values, a significant decrease in body weight $(-3.6 \pm 1.4 \%, p=0.0002)$ and body composition with reduction of body fat percentage $(-15.1 \pm 3.5 \%, p<0.0001)$ and fat mass $(-36.4 \pm 31.4 \%, p=0.022)$ was observed. Muscle performance of the upper limb was preserved. In the lower limb, monohulls skippers showed a significant reduction of jump height (-6.6 $\pm 4.8 \%$, $p=0.022)$, power $(-11.7 \pm 7.3 \%, p=0.011)$ and speed $(-14.6 \pm 7.4 \%, p=0.0006)$ while a multihulls skipper showed a gain in speed $(+0.87 \%)$, power $(+8.52 \%)$, force $(+11 \%)$ resulting in a higher jump height $(+1.12 \%)$. These changes were inversely correlated with sea days (Pearson $r$ of $-0.81,-0.96$ and -0.90 , respectively, $p<0.01$ ).

Conclusions: Changes in body weight and composition are consistent with previous data indicating a probable negative energy balance. The main finding demonstrates a difference in muscular conditioning between upper and lower limbs that might be explained by differential workload related to boat architecture (trampolines) or handling.
\end{abstract}

(Int Marit Health 2020; 71, 1: 20-27)

Key words: anthropometry, skinfold thickness, impedance, bioelectrical, weight loss, flicker fusion, muscle strength

\section{INTRODUCTION}

Ocean racing has changed a lot in the last 30 years. Boat designers have tried to find ways to increase power, while reducing weight, however with few concessions to sailor's comfort. Therefore, these high-performance racing boats tend to go faster. For instance, 60 -feet monohulls boat from the International Monohulls Open Class Association (IMOCA), completing the round-the-world solo race ("Vendee Globe": 21,638 nautical miles), decreased the time needed from under 100 days in 2001, down to 90 days in 2005,

Pierre Lafère, PhD, Department of Anaesthesiology, Erasme University Hospital, Université Libre de Bruxelles, Brussels, Belgium,

e-mail: pierre.lafere@erasme.ulb.ac.be 
below 85 days in 2009, 78 days in 2013 and to finally reach 74 days in 2017.

Consequently, boats handling has become increasingly demanding, both physically and psychologically. Indeed, offshore racing is an arduous activity involving hard mental and physical work carried out in strenuous environmental conditions. The watch system makes it impossible to get a full night sleep deterring physical and mental performance as well as meal frequency [1]. Also, according to the nature of their sport, sailors involved in offshore racing can be exposed to injuries and other health problems that can endanger their lives [2]. Unfortunately, the distance from onshore health facilities and lack of professional presence on board might explain why only scarce scientific data are available. A review based on a systematic search of medical databases employing predefined criteria, using the terms offshore racing/sailing, solo sailing or open sea racing could only identified less than 20 publications on the subject over the last 40 years [2-15]. All those studies only included a very limited number of subjects (case report to a dozen individuals), albeit a very specific population (Caucasian males in their mid-thirties) and were mostly focused on energy expenditure/intake and sleep deprivation.

More data are available about the physiological challenges of competitive sailing, for instance related to the America's Cup [16, 17], albeit this is not the exact same sailing discipline as the later ignores the continuous demanding efforts of long-haul sailing. According to a recent review [18], the most influential factors in determining sailing performance, including dinghy sailing with smaller boats like Laser or the "America's Cup" with large boats, are related to the sailor's physical characteristics, sailing techniques, decision-making abilities, tactical skills or psychological characteristics.

In competitive sailing, there are different types of boats that demand various types of effort by the sailor, which is why knowledge of their specific physical and physiological features for each type of vessel is necessary. Unfortunately, the field of ocean racing remains mostly unexplored. To find out more about this issue, the Pen Duick company (Paris, France) gave us the opportunity to carry out measurements on skippers participating in the two-handed 2009 "Transat Jacques Vabre" between Le Havre, France and Puerto Limón, Costa Rica (4335 nautical miles).

Therefore, the aim of the study was to assess global physical changes among offshore skippers with a specific focus on muscular strength after a transoceanic race.

\section{MATERIALS AND METHODS}

After being informed of the purpose and experimental procedures of the study, 8 Caucasian male skippers without any of them paired on the same boat ( 7 sailing an IMOCA and 1 sailing a Multi 50) volunteered to participate and signed a written informed consent. The study was approved by the local Academic Bio-Ethical Committee of Brussels (CE2008/66) and was conducted in accordance with the Declaration of Helsinki [19]. All participants were subjected to the same data collection procedure, which was applied before the race and within 6 hours after arrival in Puerto Limón. Therefore, each skipper is his own control.

Anthropometric measurements performed by the same qualified investigator with 5 years of experience followed the protocol of the International Society for the Advancement of Kinanthropometry (ISAK) [20] and include body mass measured to the nearest $0.05 \mathrm{~kg}$ with a digital scale (SECA 220 , Seca gmbh \& Co., Hamburg, Germany), skinfolds at six different sites (triceps, subscapular, supra-spinal, abdominal [umbilical], anterior tight, medium calf) using a Harpenden calliper (Harpenden skinfold calliper, Bay international, West Sussex, England), and girths at six different sites (arm girth relaxed, forearm, supra-patellar, thigh, mid-thigh, medial calf) with a flexible anthropometric steel tape (Lufkin W606PM, cooper industries, Ohio, United States) to the nearest $0.1 \mathrm{~cm}$. By convention, all anthropometrical measurements were taken on the right side of the body (all skippers were right-handed). Each measurement was taken twice. If the difference between the first and the second reading was $>5 \%$ for skinfolds and $>1 \%$ for girths, a third measurement was taken and the mean of the two nearest measurements was calculated as the final value. Percentage body fat (\%BF) was calculated using the Yuhasz formula (\%BF $=0.1051 \times\left(\sum 6\right.$ skinfolds) +2.585 ) [21], because it was designed for athletes and fit individuals, which is the case of our population [22].

Since biometrical multifrequency impedance analysis (BIA) is a widely accepted method for the determination of body composition (total body water [TBW], extracellular fluid [ECF] and intracellular fluid [ICF]) due to its simplicity, speed and non-invasive nature [23], we used a single channel, tetra polar bioimpedance spectroscopy device that scans 256 frequencies between $4 \mathrm{kHz}$ and $1000 \mathrm{kHz}$ for the estimation of body composition in healthy individuals (SFB7, Impedimed Inc., Carlsbad, USA). Fat-free mass (FFM) and fat mass (FM) are then calculated on the device.

Strength assessment included measurement of the maximal voluntary handgrip strength (HGS) and the vertical jump performance [24]. To avoid injury, a standard warm-up routine, consisting of jumping, stretching and gripping at submaximal intensity preceded the actual tests. HGS was measured three times with an electronic hand dynamometer (Newgen medical EH101, Pearl, Buggingen, Germany) [25] and the mean value was used for analysis and comparison. Vertical counter movement jump performance was assessed using an accelerometer (Myotest, Myotest Inc., Sion, Switzerland) [26]. A total of 5 maximal vertical jumps 
Table 1. Pre- and post-transoceanic race anthropometric data of offshore sailors $(n=8)$

\begin{tabular}{|c|c|c|c|}
\hline & Pre-race & Post-race & P (Paired t test) \\
\hline Weight [kg] & $81.8 \pm 10.1$ & $78.9 \pm 10.1$ & $0.0002 * *$ \\
\hline Body mass index $\left[\mathrm{kg} / \mathrm{m}^{2}\right]$ & $25.4 \pm 1.1$ & $24.5 \pm 1.3$ & $0.0001 * *$ \\
\hline Percentage of body fat [\%BF] & $12.2 \pm 2.4$ & $10.4 \pm 2.3$ & $<0.0001 * *$ \\
\hline \multicolumn{4}{|l|}{ Skinfold [mm]: } \\
\hline Triceps & $13.9 \pm 5.2$ & $10.6 \pm 3.7$ & $0.0019 *$ \\
\hline Subscapular & $18.5 \pm 5.2$ & $15.0 \pm 4.5$ & $0.0011^{*}$ \\
\hline Supra-spinal & $17.6 \pm 6.2$ & $14.9 \pm 5.9$ & $<0.0001^{* *}$ \\
\hline Umbilical & $25.6 \pm 6.7$ & $18.7 \pm 7.9$ & $0.0002 * *$ \\
\hline Front tight & $9.7 \pm 2.8$ & $9.5 \pm 2.5$ & 0.516 \\
\hline Medium calf & $6.4 \pm 2.6$ & $5.9 \pm 2.6$ & 0.227 \\
\hline \multicolumn{4}{|l|}{ Girth $[\mathrm{cm}]:$} \\
\hline Forearm & $29.7 \pm 1.7$ & $29.8 \pm 1.4$ & 0.557 \\
\hline Arm & $29.9 \pm 1.9$ & $30.3 \pm 1.5$ & 0.161 \\
\hline Thigh & $53.2 \pm 2.7$ & $51.7 \pm 3.0$ & $0.0025 *$ \\
\hline Mid-thigh & $45.6 \pm 3.5$ & $44.2 \pm 3.7$ & $0.0095^{*}$ \\
\hline Supra-patellar & $39.4 \pm 3.2$ & $39.1 \pm 3.2$ & 0.139 \\
\hline Medium calf & $38.0 \pm 1.3$ & $37.6 \pm 1.1$ & 0.111 \\
\hline
\end{tabular}

were evaluated and accelerometric data were stored during the assessments and subsequently downloaded for jump height $(\mathrm{cm})$, power $(\mathrm{w} / \mathrm{kg})$, force $(\mathrm{N} / \mathrm{kg})$, and speed $(\mathrm{cm} / \mathrm{s})$ calculations. The mean for each value, calculated on the three highest jumps, was used for analysis and comparison.

In the present study, non-muscular fatigue (central) was assessed by means of Critical Flicker Fusion Frequency (CFFF) and by a 100-mm visual analogue scale (VAS). CFFF was assessed with a specific watertight device (Human Breathing Technology, Trieste, Italy) previously fully described by Balestra et al. [27]. Thanks to the design of the device, it is impossible for the subjects to be aware of the actual flicker frequency through the whole test. When there is a change in LED light from fusion to flicker (or flicker to fusion), the subject acknowledges it to the investigator and the reached frequency is recorded. For each sample, the mean of three consecutive tests was calculated and used for analysis. For VAS testing, we used the same methodology as in Lafère et al. [28] where the same VAS scale is presented twice but in opposite directions: one asked to evaluate the 'energy level' (from sleepy/0 to energetic/10), the second asked to evaluate the "tiredness level" (from energetic/0 to sleepy/10). Should the difference between the first and the second reading be $>10 \%$, a third measurement ("tiredness level") was taken and the mean of the two nearest measurements was calculated as the final value.
Since all data passed the Kolmogorov-Smirnov test, allowing us to assume a Gaussian distribution, they were analysed with a Student's paired t-test or a one-way ANOVA with Bonferroni post-hoc test.

Since each skipper is his own control, taking the pre-race values as $100 \%$, percentage changes were calculated for each parameter, allowing an appreciation of the magnitude of change between each measurement rather than the absolute values.

Existing correlation between significant statistical results and age, initial weight or days at sea was assessed through a Pearson correlation coefficient test and linear regression when possible.

All tests were performed using a standard computer statistical package, GraphPad Prism version 5.00 for Windows (GraphPad Software, San Diego California USA). A threshold of $p<0.05$ was considered statistically significant. All data are presented as mean \pm standard deviation (SD).

\section{RESULTS}

The mean age of the 8 subjects was $39.7 \pm 5.3$ years and height $1.79 \pm 0.97 \mathrm{~m}$. All other anthropometric characteristics pre- and post-race are summarised in Table 1. We observed a significant decrease in body weight (-3.6 \pm $\pm 1.4 \%$ ) from $81.8 \pm 10.1$ to $78.9 \pm 10.1 \mathrm{~kg}(p=0.0002$, paired t-test, $\mathrm{df}=7$ ) and a similar significant reduction of 


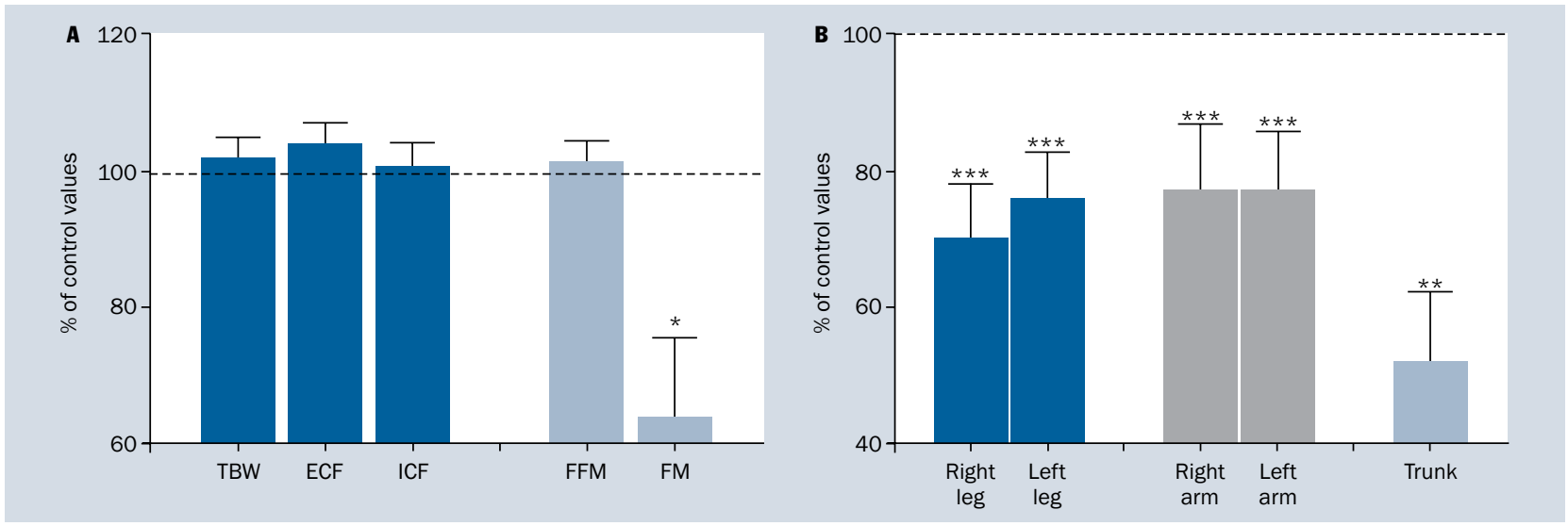

Figure 1. Percentage variation of global impedancemetry $(A)$ and segmental fat mass $(B)$ after a transoceanic race $(n=8)$. Pre -race value is taken as $100 \%$. Each subject is compared to his own pre-race value. Means and standard deviations are shown in graph; ${ }^{* *} \mathrm{p}<0.001 ;{ }^{* *} \mathrm{p}<0.01$; ${ }^{*} \mathrm{p}<0.05$; TBW - total body water; ECF - extracellular fluid; ICF - intracellular fluid; FFM - free fat mass; FM - fat mass

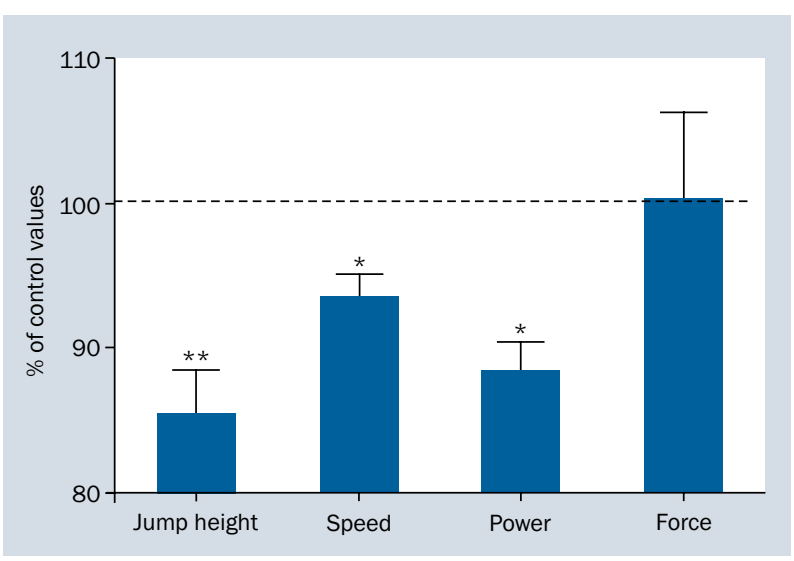

Figure 2. Percentage variation of lower limb muscle performance after a trans-oceanic race $(n=8)$. Pre-race value is taken as $100 \%$. Each subject is compared to his own pre-race value. Means and standard deviations are shown in graph; $* * p<0.001 ; * p<0.05$

the body mass index (BMI: $-3.2 \pm 1.7 \%$ ) from $25.4 \pm 1.1$ to $24.5 \pm 10.3 \mathrm{~kg} / \mathrm{m}^{2}(p=0.0001$, paired t-test, $\mathrm{df}=7)$. Based on skinfold measurements and the Yuhasz formula, this weight reduction seems to be associated with a modification of body composition with a significant reduction of the $\% \mathrm{BF}$ $(-15.1 \pm 3.5 \%)$ from $12.2 \pm 2.4$ to $10.4 \pm 2.3 \%$ ( $p<0.0001$, paired t-test, $\mathrm{df}=7$ ). However, this modification seems to be at the expense of the upper body with some significant decreased skinfolds at tricipital, subscapular, supra-spinal and umbilical level. No significant changes were identified on the lower limb. Unlike skinfold measurement, muscle circumference did not show significant change in the upper limb, while a significant decrease was noticed in the lower limb at mid-tight and maximal thigh level.

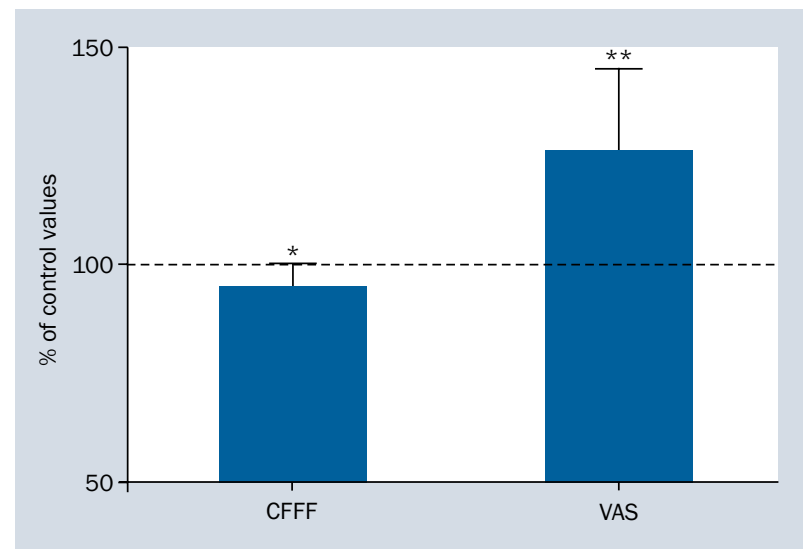

Figure 3. Percentage variation of perceived fatigue after a trans-oceanic race $(n=8)$. Pre-race value is taken as $100 \%$. Each subject is compared to his own pre-race value. Means and standard deviations are shown in graph; ${ }^{*} p<0.001$; ${ }^{*}<<0.05$; CFFF - Critical Flicker Fusion Frequency; VAS - Visual Analog Scale

Analysis of body composition by BIA (Fig. 1) showed no difference in hydration (TBW: from $55.4 \pm 6.0$ to $55.8 \pm 5.3 \%$ of total weight, $p=0.571$; ECF: from $22.7 \pm 3.0$ to $23.3 \pm$ $\pm 3.8 \%$ of total weight, $p=0.307 ;$ ICF: $32.7 \pm 3.2$ to $32.4 \pm$ $\pm 1.6 \%$ of total weight, $p=0.878$, paired t-test, $\mathrm{df}=6)$ and FFM values $(75.7 \pm 8.2$ to $75.7 \pm 7.2 \mathrm{~kg}, \mathrm{p}=0.878$ paired t-test, df $=6)$. However, we observed a significant reduction of FM ( $-36.4 \pm 31.4 \%)$ from $6.6 \pm 4.1$ to $3.2 \pm 0.9 \mathrm{~kg}$ $(p=0.022$ paired t-test, $d f=6)$. Segmental impedance indicated that this reduction in fat mass is evenly distributed between the different segments of the body. Although the trunk presented the greater reduction of fat mass $(-48.3 \pm$ $\pm 28.1 \%$ ), this result is not significant ( $p=0.247$, one-way ANOVA, $F(4,30)=1,433)$. 

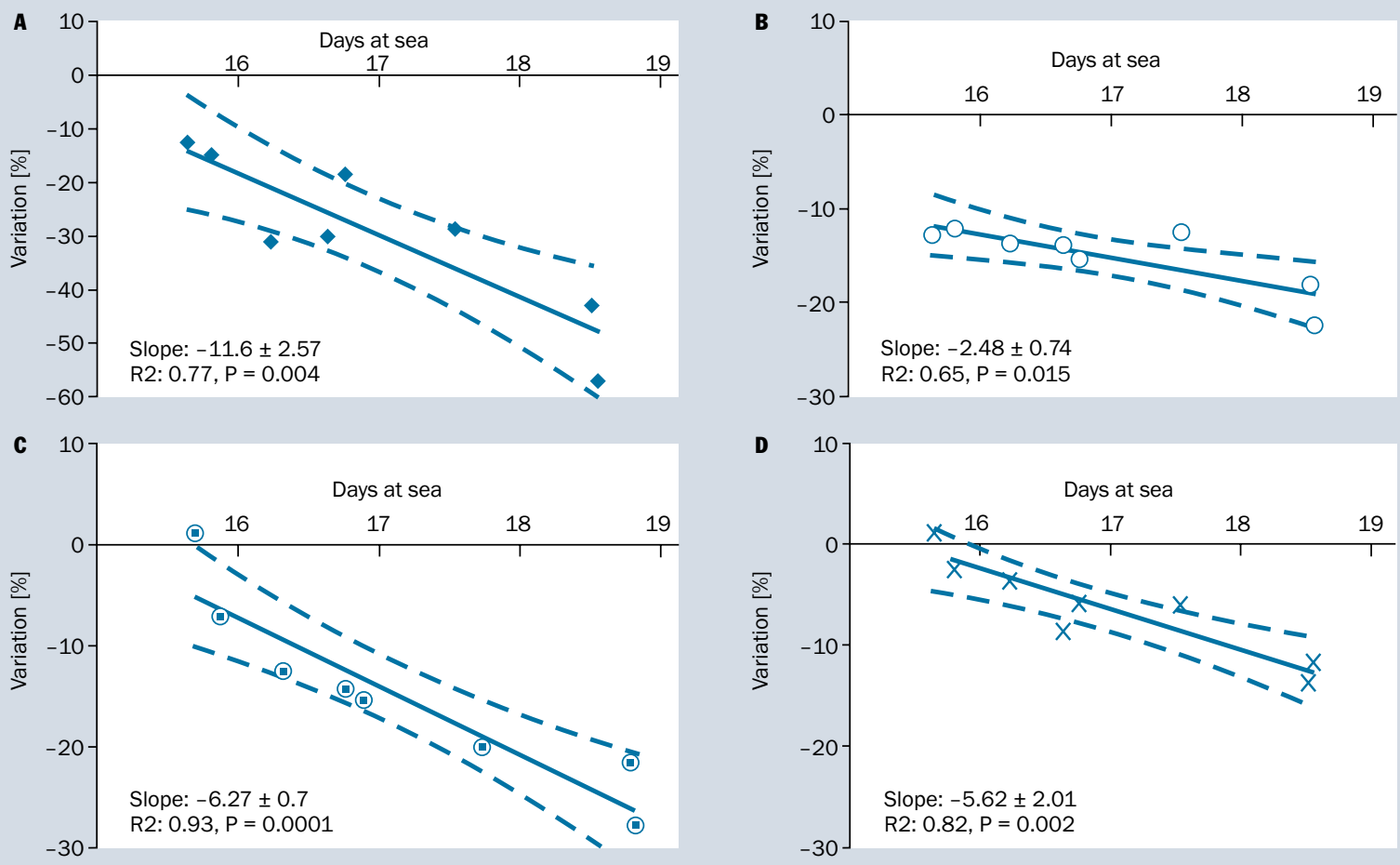

Figure 4. Correlation calculation and linear regression of the magnitude umbilical skinfold (A), body fat (\%BF) (B), jump height (C) and speed (D) changes and days at sea $(n=8)$.

Muscle performance of the upper limb seemed to be preserved as HGS values did not change significantly after the race from $53.6 \pm 8.3$ to $51.8 \pm 8.7 \mathrm{~N}(p=0.228$, paired t-test, $d f=7)$. On the contrary, results of the lower limb showed significant impairment (Fig. 2). The speed (-6.6 \pm $\pm 4.8 \%$ ) and power $(-11.7 \pm 7.3 \%)$ developed by the extensor muscles of the lower limbs during counter movement jumps decreased from $237.8 \pm 30.3$ to $221.8 \pm 28.0 \mathrm{~cm} / \mathrm{s}$ $(p=0.022$, paired t-test, $d f=7)$ and from $44.8 \pm 7.8$ to $39.7 \pm 8.9 \mathrm{w} / \mathrm{kg}(\mathrm{p}=0.011$, paired t-test, $\mathrm{df}=5)$. Jump height was also significantly decreased $(-15.5 \pm 7.4 \%)$ from $29.3 \pm 6.3$ to $25.4 \pm 6.1 \mathrm{~cm} \mathrm{(} p=0.0006$, paired t-test, $\mathrm{df}=7)$. However, the force $(\mathrm{N} / \mathrm{kg})$ developed by the same muscles, did not show any significant difference between measurements made before and after the race (Force: $22.8 \pm$ \pm 3.1 vs. $22.4 \pm 2.0 \mathrm{~N} / \mathrm{kg}, \mathrm{p}=0.930$, paired t-test, $\mathrm{df}=7$ ).

Perceived fatigue was significantly higher after the race (Fig. 3). Subjective evaluation (VAS) showed an increase of $25.9 \pm 19.3 \%$ in the level of tiredness at $126 \pm 19.3 \%$ of pre-race value $(p=0.0067$, paired t-test, $d f=7)$, while objective evaluation of cerebral arousal showed a consistent decrease in CFFF by $5.6 \pm 5.7 \%$ of CFFF at $94.4 \pm 5.8 \%$ of pre-race value ( $p=0.028$, paired t-test, $d f=7$ ).

To depict the magnitude of the race, the first multi 50 raced for 5050 nautical miles and crossed the line after 15 days 15 hours, 31 minutes while the first IMOCA crossed the line a few hours later after 15 days 19 hours and 22 minutes and 4730 nautical miles of travelled distance. Our last volunteer crossed the finish line after 18 days 13 hours and 26 minutes. A Pearson correlation calculation demonstrated that the magnitude of umbilical skinfold, \%BF, jump height and speed changes were inversely correlated with days at sea (Pearson $r$ of $-0.87,-0.81,-0.96$ and -0.90 , respectively; Fig. 4). Since all differences reached statistical significance $(p<0.01)$, we can reject the idea that the correlation is due simply to random sampling. This relation is further confirmed by linear regression. No other correlation could be found between statistically significant results and age or initial weight.

\section{DISCUSSION}

Measuring physiological parameters during sailing races is technically and logistically difficult. Nonetheless, this study contributed valuable data on global physical changes in the 2009 "Transat Jacques Vabre", a two-handed offshore sailing race.

Previous studies demonstrated that professional sailors incur severe sleep loss with marked performance impairment [8-11]. In case of prolonged sleep restriction, the balance between sleep homeostasis and circadian rhythm 
process is disturbed, which induces an adaptive response. Pressure for sleep during wakefulness increases and dissipates exponentially during subsequent sleep, hence the efficacy of brief periods of sleep providing significant performance recuperation. However, sleep restriction practiced on a chronic basis induces cumulative performance deficits [29]. Our results confirmed an increased perceived fatigue both on subjective (VAS) and objective assessment (CFFF). Indeed, CFFF has been used with success in several models of extreme exposure such as divers [28, 30], pilots [31] or parabonauts [32] and has been seen as a global index of cerebral arousal, however with an easier set-up. Since, it was demonstrated on short races that it was possible to minimise anxiety and perceived fatigue with adequate sleep to optimise performance and efficiency [8], it implies that an improved arousal may be a surrogate of an improved performance. We therefore advocate introducing CFFF measurement into skipper's individual assessment to better identify the optimal moment or need for sleep.

As already demonstrated in several studies [4, 5, 7, 33], we observed a significant reduction of bodyweight (-3.6 \pm $\pm 1.4 \%)$ at the expense of FM (-36.4 $\pm 31.4 \%)$. According to segmental BIA of FM, the reduction of fat mass was more pronounced in the abdomen $(-48.3 \pm 28.1 \%)$ than in the limbs (-25.1 $\pm 22.5 \%)$. Although not statistically significant, this trend makes sense as abdominal adipose tissue (both visceral and subcutaneous) represents about $45 \%$ of the total adipose tissue volume among lean men between 39 and 49 years [34]. Since it was not possible to assess the daily nutritional intake, we can only assume a negative energy balance. The hypothesis of negative energy balance makes sense in regards of the significant reduction of waist circumference. Indeed, according to different studies the mean total daily energy expenditure during offshore race may vary between 14.5 [33] and $19.3 \mathrm{MJ} / \mathrm{d}$ [4], which is very high. More, it was demonstrated on an offshore race of 500 nautical miles long that the time spent performing sedentary (<1.5 METs, excluding sleeping) or light activity (between 1.5 and $2.9 \mathrm{METs}$ ) predominates with an average of $92 \%$ of the wake time [11]. This may be assimilated to an endurance exercise known to increase the maximum consumed oxygen, improve the capability of skeletal muscles to produce energy via the aerobic system and to reduce weight [35].

The main finding of our study reports a difference in muscular conditioning between upper and lower limbs. Indeed, no loss of HGS was noticed while there is a clear and significant impairment of the leg physical capacity with a reduction of jump height, speed and power. A recent case report has produced similar result after an oceanic race that lasted 64 days [1]. According to this report, this is explained by a leg disuse responsible for a decreased maximum oxygen uptake and maximum workload during cycling measured 10 days after completion of the race. A deeper look at skinfolds and muscle circumferences could explain this difference. In the upper limb, we noticed a significant reduction of skinfolds, confirming the loss of fat, while arm and forearm circumferences are not modified suggesting a gain of muscle. On the opposite, in the lower limbs, the skinfolds are not modified, while there is a significant reduction of the circumference of the thigh suggesting a loss of muscle. Analysis of the different muscular activities when on board, could explain these results. Activity of the lower limbs is essentially static, often sub-maximal whereas upper limbs activity, during race, is explosive and often maximal (using grinders and winches to shape the sails in coordination with the trimmers boat) [36]. When outside, sailors usually stay in the cockpit located at the helm, where the majority of ropes are positioned, allowing for sails adjustments. Except in the event of changing and reefing sails, skippers avoid moving towards the bow. When inside, the available room does not allow the skippers to maintain an upright position, except for the smaller ones or when the boat goes upwind. They remain seated in front of the chart table, in order to receive and study the weather forecasts, calculate the best route, or during bad weather conditions. This can be clearly considered as a lower limb detraining [37]. Indeed, it is agreed that if activity is sufficiently reduced, muscle atrophy will ensue with associated loss of force and power [38, 39]. It is further interesting to note that all of the participants within the study decreased their performance (i.e. losing strength in the lower limb) with one exception. Indeed, the only skipper of our sample engaged in multi 50 conserved his leg functionalities. He even ameliorated them with a gain in speed $(+0.87 \%)$, power $(+8.52 \%)$ and force (+11\%) resulting in a higher jump height (+1.12\%). A shorter stay at sea compared to the other sailors might explain this. However, when compared to the fastest IMOCA participants, who arrived within hours of the multi 50 (difference of $3 \mathrm{~h} 50 \mathrm{~min} 20 \mathrm{~s}$ ), the slope of the curve between pre-and postrace results are significantly different. We can hypothesize that the presence of "trampolines" set between the portside/starboard hulls and the main hull could be responsible for this. Indeed, continuously crossing of the trampolines to manoeuvre the boat requires greater range of motion in lower limbs, with increased torque and bigger flexion allowing more intense muscular recruitment in this type of activity [40] preserving leg physical capacity.

Although both fatigue and loss of weight after an offshore race were previously demonstrated, this provides some external validity to our results. However, we were surprised by the extent of the reported changes and the difference that a few days can make in weight, body composition and performance. Since we were limited by logistical constraint and a very specific population, our sample was small. This 
may have biased our results. However, using each skipper as his own control mitigated any risks of underestimating or overestimating the magnitude of the changes.

\section{CONCLUSIONS}

Even if our sample size was small, including only $20 \%$ of skippers engaged in the race, we showed race-induced impairment of fatigue, body weight, body composition, and leg physical capacity. The results of this study confirmed previous data but on a larger scale same race. Although it does not allow us to determinate which phenomena are directly implicated, we could say that the subjective feeling of weakness of the lower limbs experienced by sailors seems to be multifactorial: nervous system plasticity, loss and/or fibre modifications.

The results of our study lead to a reflexion on the necessity of conceiving specific trainings for IMOCA class sailors. Indeed several factors (sleep time, eating habits, sufficient hydration, etc.), have become essential in preparation, and for success of ocean racing. In addition to these factors biometrical and strength changes induced by this type of competition should be considered. This could help the development of specific training program or exercises while at sea to prevent such leg detraining.

\section{ACKNOWLEDGEMENTS}

This study was carried out on own funds and did not benefit from any external funding.

The authors wish to thank all the skippers who took the time to participate to this study, especially among arrival after a long stay at sea, even before reuniting with their family and friends.

\section{REFERENCES}

1. Ghiani G, Magnani S, Doneddu A, et al. Case study: physical capacity and nutritional status before and after a single-handed yacht race. Int J Sport Nutr Exerc Metab. 2018; 28(5): 558-563, doi: 10.1123/ ijsnem.2017-0345, indexed in Pubmed: 29252058.

2. Nikolić N, Nilson R, Briggs S, et al. A Medical Support in Offshore Racing - Workshop on Medical Support for Offshore Yacht Races, Telemedical Advice Service (TMAS), 1-2 December 2018, London, United Kingdom. Int Marit Health. 2019; 70(1): 27-41, doi: 10.5603/ IMH.2019.0005, indexed in Pubmed: 30931515.

3. Bernardi M, Felici F, Marchetti M, et al. Cardiovascular load in off -shore sailing competition. J Sports Med Phys Fitness. 1990; 30(2): 127-131, indexed in Pubmed: 2402130.

4. Branth S, Hambraeus L, Westerterp K, et al. Energy turnover in a sailing crew during offshore racing around the world. Med Sci Sports Exerc. 1996; 28(10): 1272-1276, doi: 10.1097/00005768199610000-00010, indexed in Pubmed: 8897384.

5. Bigard AX, Guillemot PY, Chauve JY, et al. Nutrient intake of elite sailors during a solitary long-distance offshore race. Int J Sport Nutr. 1998; 8(4): 364-376, doi: 10.1123/ijsn.8.4.364, indexed in Pubmed: 9841957.
6. Portier H, Chatard JC, Filaire E, et al. Effects of branched-chain amino acids supplementation on physiological and psychological performance during an offshore sailing race. Eur J Appl Physiol. 2008; 104(5): 787-794, doi: 10.1007/s00421-008-0832-5, indexed in Pubmed: 18704484.

7. Fearnley D, Sutton L, O'Hara J, et al. Case study of a female ocean racer: prerace preparation and nutritional intake during the Vendée Globe 2008. Int J Sport Nutr Exerc Metab. 2012; 22(3): 212-219, doi: 10.1123/ijsnem.22.3.212, indexed in Pubmed: 22349112.

8. Hagin V, Gonzales BR, Candau RB, et al. Influence of a conservative sleep management strategy during a solo Pacific Ocean crossing on anxiety and perceived fatigue: a case study. J Sports Sci. 2012; 30(4): 395-402, doi: 10.1080/02640414.2011.644248, indexed in Pubmed: 22242936.

9. Hurdie R, Monaca C, Mauvieux B, et al. Field study of sleep and functional impairments in solo sailing races. Sleep and Biological Rhythms. 2012; 10(4): 270-277, doi: 10.1111/j. 1479-8425.2012.00570.x.

10. Hurdiel R, Van Dongen HPA, Aron C, et al. Sleep restriction and degraded reaction-time performance in Figaro solo sailing races. J Sports Sci. 2014; 32(2): 172-174, doi: 10.1080/02640414.20 13.815359, indexed in Pubmed: 24015907.

11. Galvani C, Ardigo LP, Alberti M, et al. Physical activity, sleep pattern and energy expenditure in double-handed offshore sailing. J Sports Med Phys Fitness. 2015; 55(12): 1480-1488, indexed in Pubmed: 25323483.

12. Loddé $B$, Mahé $C$, Jacolot $L$, et al. Skin diseases affecting high-level competition sailors: descriptive study carried out during the 2012 AG2R transatlantic boat race. Wilderness Environ Med. 2016; 27(1): 39-45, doi: 10.1016/j.wem.2015.10.011, indexed in Pubmed: 26948552.

13. Nikolić N, Denisenko I, Nilson R, et al. A Medical Support in Offshore Racing Workshop, 6 November 2015, Sanya, China. Int Marit Health. 2016; 67(4): 255-259, doi: 10.5603/IMH.2016.0045, indexed in Pubmed: 28009393.

14. Nikolić N, Horneland AM, Denisenko I, et al. A Medical Support in Offshore Racing Workshop on Learning Competences/Outcomes, 4-5 November 2016, Barcelona, Spain. Int Marit Health. 2017; 68(3): 178-182, doi: 10.5603/IMH.2017.0033, indexed in Pubmed: 28952666.

15. Nikolić N, Nilson R, Briggs S, et al. A Medical Support in Offshore Racing - Workshop on Medical Kit Inventory in Offshore Yacht Racing, 12-13 May 2017, Lorient, France. Int Marit Health. 2018; 69(3): 214-222, doi: 10.5603/IMH.2018.0035, indexed in Pubmed: 30270422.

16. Neville V, Gant N, Folland JP. Thermoregulatory demands of elite professional America's Cup yacht racing. Scand J Med Sci Sports. 2010; 20(3): 475-484, doi: 10.1111/j.1600-0838.2009.00952.x, indexed in Pubmed: 19558386.

17. Adami PE, Delussu AS, Rodio A, et al. Upper limb aerobic training improves aerobic fitness and all-out performance of America's Cup grinders. Eur J Sport Sci. 2015; 15(3): 235-241, doi: 10.1080/17 461391.2014.971878, indexed in Pubmed: 25357134.

18. Serrano AM, Segado FS, Antùnez RM. Decisive factors in sailing performance: literature review. Cultura, Ciencia y deporte. 2012; 20(7): 125-134.

19. General Assembly of the World Medical A. World Medical Association Declaration of Helsinki: ethical principles for medical research involving human subjects. J Am Coll Dent. 2014; 81(3): 14-18, indexed in Pubmed: 25951678. 
20. Norton K, Whittingham N, Carter L, et al. International Standards for Anthropometric Assessment. Underdale, SA, Australia: International Society for the Advancement of Kinanthropometry; 1996.

21. Yuhasz MS. Physical fitness and sports appraisal laboratory manual. Canada: University of Western Ontario, London 1974.

22. Norgan NG. Laboratory and field measurements of body composition. Public Health Nutr. 2005; 8(7A): 1108-1122, doi: 10.1079/ phn2005799, indexed in Pubmed: 16277823.

23. Jaffrin MY, Morel H. Body fluid volumes measurements by impedance: A review of bioimpedance spectroscopy (BIS) and bioimpedance analysis (BIA) methods. Med Eng Phys. 2008; 30(10): 1257-1269, doi: 10.1016/j.medengphy.2008.06.009, indexed in Pubmed: 18676172.

24. Vanrenterghem J, Lees $\mathrm{A}$, Lenoir $\mathrm{M}$, et al. Performing the vertical jump: movement adaptations for submaximal jumping. Hum Mov Sci. 2004; 22(6): 713-727, doi: 10.1016/j.humov.2003.11.001, indexed in Pubmed: 15063050.

25. Schlüssel MM, dos Anjos LA, de Vasconcellos MT, et al. Reference values of handgrip dynamometry of healthy adults: a population -based study. Clin Nutr. 2008; 27(4): 601-607, doi: 10.1016/j. clnu.2008.04.004, indexed in Pubmed: 18547686.

26. Casartelli N, Müller R, Maffiuletti NA. Validity and reliability of the Myotest accelerometric system for the assessment of vertical jump height. J Strength Cond Res. 2010; 24(11): 3186-3193, doi: 10.1519/ JSC.0b013e3181d8595c, indexed in Pubmed: 20940642.

27. Balestra $C$, Lafère $P$, Germonpré $P$. Persistence of critical flicker fusion frequency impairment after a $33 \mathrm{mfw}$ SCUBA dive: evidence of prolonged nitrogen narcosis? Eur J Appl Physiol. 2012; 112(12): 4063-4068, doi: 10.1007/s00421-012-2391-z, indexed in Pubmed: 22476770.

28. Lafere P, Balestra C, Hemelryck W, et al. Evaluation of critical flicker fusion frequency and perceived fatigue in divers after air and enriched air nitrox diving. Diving Hyperb Med. 2010; 40(3): 114-118, indexed in Pubmed: 23111908.

29. Van Dongen HPA, Dinges DF. Sleep, circadian rhythms, and psychomotor vigilance. Clin Sports Med. 2005; 24(2): 237-49, vii, doi: 10.1016/j.csm.2004.12.007, indexed in Pubmed: 15892921.

30. Lafère $P$, Balestra $C$, Hemelryck W, et al. Do environmental conditions contribute to narcosis onset and symptom severity? Int J Sports Med. 2016; 37(14): 1124-1128, doi: 10.1055/s-0042-110573, indexed in Pubmed: 27737486.
31. Truszczyński O, Wojtkowiak M, Biernacki M, et al. The effect of hypoxia on the critical flicker fusion threshold in pilots. Int J Occup Med Environ Health. 2009; 22(1): 13-18, doi: 10.2478/v10001009-0002-y, indexed in Pubmed: 19342364.

32. Balestra C, Machado ML, Theunissen S, et al. Critical flicker fusion frequency: a marker of cerebral arousal during modified gravitational conditions related to parabolic flights. Front Physiol. 2018; 9: 1403, doi: 10.3389/fphys.2018.01403, indexed in Pubmed: 30333762.

33. Myers SD, Leamon SM, Nevola VR, et al. Energy expenditure during a single-handed transatlantic yacht race. Br J Sports Med. 2008; 42(4): 285-288, doi: 10.1136/bjsm.2007.041533, indexed in Pubmed: 18048436.

34. Ulbrich EJ, Nanz D, Leinhard OD, et al. Whole-body adipose tissue and lean muscle volumes and their distribution across gender and age: MR-derived normative values in a normal-weight Swiss population. Magn Reson Med. 2018; 79(1): 449-458, doi: 10.1002/ mrm.26676, indexed in Pubmed: 28432747.

35. Sekhavati E, Nikseresht A, Najafian M, et al. Investigation of aerobic training and electrical motivation impacts on body fat decrease. J Med Life. 2015; 8(Spec Iss 3): 101-106, indexed in Pubmed: 28316674.

36. Bernardi M, Quattrini FM, Rodio A, et al. Physiological characteristics of America's Cup sailors. J Sports Sci. 2007; 25(10): 1141-1152, doi: 10.1080/02640410701287172, indexed in Pubmed: 17613738.

37. Mujika I, Padilla S. Detraining: loss of training-induced physiological and performance adaptations. Part l: short term insufficient training stimulus. Sports Med. 2000; 30(2): 79-87, doi: 10.2165/00007256200030020-00002, indexed in Pubmed: 10966148.

38. Demangel R, Treffel L, Py G, et al. Early structural and functional signature of 3-day human skeletal muscle disuse using the dry immersion model. J Physiol. 2017; 595(13): 4301-4315, doi: 10.1113/ JP273895, indexed in Pubmed: 28326563.

39. Theilen NT, Kunkel GH, Tyagi SC. The role of exercise and TFAM in preventing skeletal muscle atrophy. J Cell Physiol. 2017; 232(9): 2348-2358, doi: 10.1002/jcp.25737, indexed in Pubmed: 27966783.

40. Behm DG, Muehlbauer T, Kibele A, et al. Effects of Strength Training Using Unstable Surfaces on Strength, Power and Balance Performance Across the Lifespan: A Systematic Review and Meta-analysis. Sports Med. 2015; 45(12): 1645-1669, doi: 10.1007/s40279015-0384-x, indexed in Pubmed: 26359066. 